quences of recruitment difficulties. Having a good personnel department helps. My own view is that there should be one member of the personnel department with responsibility solely for medical staff.

\section{Academic sub-department}

An academic sub-department of Psychological Medicine (University of Wales College of Medicine) has now been established at the North Wales Hospital, Denbigh and Dr Grey Wilkinson has been appointed its Director.

\section{Counselling}

The clinical tutor is usually the first person trainees come into contact with when joining a scheme and plays a central role for the trainee throughout his/her rotation. The tutor is in a position of trust for the trainee, and is in a central position to know of the trainee's progress and personal as well as academic difficulties. I have found that trainees coming to our rotation may have difficulties in settling down, and there may be problems with culture, separation from family, uncertainties about career choice etc.

\section{Committee work}

The clinical tutor in this area is expected to attend two Postgraduate Boards. In addition I served as a member of the Research Committee of the Institute of Health Studies in Clwyd.

I found that I became a regular commuter to South Wales to attend meetings with representatives from the various psychiatric hospitals around Wales. This was a none too easy car drive of over 150 miles one way, and the public transport links between the two areas are poor. I attended the Working Party of Clinical Tutors for Wales as well as the Senior Registrar Subcommittee of the Joint Planning Advisory Committee. On these committees I found that I had to represent an area with very different problems and needs from some of the South Wales areas which were closer to the academic centre.

\section{Senior registrar scheme}

The clinical tutor was also expected to supervise the senior registrar training when I took over the post.
This involved two senior registrars at the time although this has now expanded to three. I have organised a rotational training scheme for senior registrars involving rotation of registrars between various posts in Gwynedd and Clwyd, as well as providing experience in psychogeriatrics.

In 1988 the Joint Committee on Higher Psychiatric Training accredited our senior registrar training scheme but the local scheme was seen as being too small to be self-contained and viable and it was recommended that the scheme form part of a larger one. Thus we have decided to merge with the South Wales scheme, although in view of the distances involved the local rotation will probably need to maintain some degree of independence, as it would be difficult for senior registrars to work on schemes where they have to rotate to hospitals over 150 miles apart.

\section{Academic work}

As clinical tutor I have organised and attended regular case conferences and lectures by visiting speakers. I have delegated the task of organising the journal club to the senior registrars. Our trainees attend the University Department at the Royal Liverpool Hospital for the MRCPsych course.

As in other schemes, in my experience locally, trainees have very rarely been able to do their own research. However there are exceptions and, with the establishment of the new academic centre, and improvement in recruitment, trainees may be more able and keen to do original work.

Thus over the last few years that I have been a clinical tutor for North Wales I have seen a number of changes occurring in psychiatric training locally. Our training has been improved with the help of College inspection teams who have given us helpful advice. In addition the setting up of an academic department locally forms a precedent for North Wales and will further enhance training in psychiatry. Recruitment is now much less of a problem and I am now ready to pass on the baton of clinical tutor to my successor with some confidence that psychiatric training in North Wales has been established on a firm footing.

\title{
Undesirable reading: the real role of the clinical tutor
}

\author{
Tom Walmsley, Psychiatric Tutor, Knowle Hospital, Fareham PO17 5NA
}

I was appointed clinical tutor at Knowle Hospital seven years ago with little idea of what my responsibilities would be. From the College literature (which
I have not found very helpful) it seemed I was responsible in a more or less indirect way for the psychiatric education of most of those working in the hospital as 
well as of those local general practitioners who might refer patients here. In addition, all medical students in the place are my responsibility - a considerable number of young people. To complicate this task, our academic unit had moved out of Knowle two years before my arrival and new trainees were advised that Knowle Hospital (usually described as a 'traditional Victorian mental hospital') would be closing in the near future as modern community services were provided. Finally, the advent of proper management, welcomed by me, was spoiled by an indifference to psychiatric education which bordered on absurdity.

What was to be done in such circumstances? Here, I wish to record my own responses which have been halting and inadequate in the hope that those charged with similar tasks in the future might find such undesirable reading to be of use: To warn and to advise.

\section{The central task}

I believe the central task of the tutor to be the setting up of an educational way of working for the junior doctors in his charge. In doing this, the tutor acts as one of a team of consultants and he must work on his consultant peers first. Each consultant has different interests and difficulties to bring to the trainees' attention; most hospitals have someone interested in psychotherapy, another doctor obsessed with the Mental Health Act, another consultant with an interest in physical treatments as well as some who fail to have any distinctive features at all. There are also lazy and precarious consultants who pose a very considerable problem for tutors.

What is the role of the tutor in such a group? He is not its manager or conductor as other people are paid to do that job. Rather, his role is to organise the exposure of trainees to consultants in such a way that their anxiety is minimised and their understanding is enhanced. The tutor might be called the sapiential consultant to the hospital team; he must make the most of what the hospital has to offer and advertise its wares as widely as possible. In addition, he should ensure the future of the hospital as an educational institution; this means explaining the importance of library and information facilities to hospital managers at every opportunity.

The setting of the educational tone is quite difficult. Undue deference from trainees, bullying infantile consultants and indifference from administrative staff can conspire to make the tutor's life hell. Visits by the College approval teams are a useful weapon for the tutor who should mention them at consultants' meetings every three months or so.

Rebel trainees are an uncommon problem. At appointments committees the tutor must be on the lookout for 'rotation-hoppers' who are forever dissatisfied with consultants who never give them enough. Bad apples like this can cause widespread discontent until their attention is drawn to an even better rotation down the road. Then they go away.

Non-medical staff come to the tutor's attention in everyday clinical work. My experience is that personal qualities of other professionals mark them out as helpers in the educational task irrespective of their professional labels. At Knowle, nurses, occupational therapists and social workers have proved themselves to be superlative teachers of psychiatry; each of these professions has also produced an outstandingly bad teacher. To a limited extent, the trainees know the good from the bad, so the tutor must find a form of words for relieving an over-stretched teacher from additional tiresome commitments.

Another area of relationship is with the local medical school. A hospital with a large number of undergraduates passing through it must possess a medical secretary with administrative abilities. If a teacher fails to materialise, it is essential that a substitute and an explanation (however fanciful) is forthcoming. Teaching psychiatry to medical students means fashioning psychological ideas to a medical formula which is laughable in its oversimplification. The tutor should take some lead in establishing the style of undergraduate psychiatry and then delegate it as quickly and extensively as possible to a nearby senior registrar. This person is better equipped to answer questions about recent advances in neurochemistry and so on.

The academic department is a different kettle of fish. In general, university departments have wasted away to an extraordinary degree in recent times and everyone seems to be on trial. These people need help and encouragement to see that teaching psychiatry to medical students is an extraordinary and privileged way of life. Other than that, there is little to be offered in the way of consolation. On the other hand, tutors should expect a good deal of stick from the university about standards of teaching and various other matters, which vary from month to month. When this becomes unbearable I issue weekly countercomplaints about the students being late or overcasual in their dress. Then the university's complaints stop for a few months.

These remarks describe the central task of the tutor and exemplify it in a few instances. Now I shall turn to more momentous occasions and show how the tutor can turn them to the trainees' (and his own) advantage.

\section{Institutional ceremonies}

Ideally, all ward rounds consist of two consultants disputing psychiatric matters in front of their trainees and representatives of other professions. In 
this way, the dialectic of medicine (diagnosis, treatment and prognosis) can be fairly represented. Ideally, each trainee should spend one hour per week in an interview without agenda with his or her consultant to discuss whatever seems to be the problem at the time.

Case conferences and journal clubs are the sacramental occasions at which the tutor can play priest. The classical case conference is an exercise in the presentation and discussion of a single case. Usually the trainee is too nervous and requires some friendly encouragement at the start and mildly honest feedback at the end. The use of audio-visual aids varies from time to time and should be sensible but discrete. A well chosen nurse is an invaluable catalyst to the understanding of the patient. Social workers often talk for too long. Not more than three people should be involved in this phase of history giving. The interview with the patient is the main event and should never veer into exhibitionism. A video interview is a satisfactory but unequal substitute. A careful arrangement of seating can put the patient in the audience and the clinician on display. Hospitals should swap consultants for these occasions. Discussion of the case may take the form of gladiatorial exhibitions of intellectual virtuosity. Once in a while, this is quite fun. Unfortunately, it is addictive for clever consultants who do not understand much about people. These collusive gladiators can be undone by a carefully mismanaged and uncomprehending remark from the tutor. Reference to the epistemic needs of the medical students or carefully misstated references usually do the job of untangling these intellectual Tarzans from their various states of spiritual estrangement and decay.

Journal clubs exist to teach trainees how to read papers and sense their methodical deficiencies. Again, this classical form has much to recommend it and can encourage a questioning and critical turn of mind. Less attractively, it becomes extremely boring as it is repeated week in, week out. My recommendation is to run three terms of 12 weeks, each term consisting of about seven classical critiques. These are punctuated by talks from national celebrities on their current interests and local people about their own jobs. At Knowle, talks from the pharmacist and the physiotherapist about their contributions to psychiatry have been very rewarding. The art therapist took the doctors to her room and photographed them collaborating on a group painting. The consultants should present papers from time to time to show how it can be done and to foster their attendance and personal psychiatric interests. Drug lunches are always promotional but can safely happen once or twice a term. Evening lectures are a lost cause, however good the advertising. Once the doctor of the '80s has gone home, home is where he will stay. Alcohol is best not served at educational functions because it interferes with their remembrance.

Careful use of these institutional ceremonies affords the tutor the main techniques of educational advance. Multi-consultant ward rounds, individual trainer-trainee interviews, co-operative case conferences, unpredictable journal clubs and occasional guest lectures are the five tools of the educational effort. By themselves, they are not enough. But they do provide the habits of an institution and protect the trainees from messianic developments in odd consultants who live in worlds of their own. The tutor carries the responsibility for a teaching matrix which is plurally consultant and self-correcting; and which will ensure his own dismissal when he is past his best. In the meantime, the tutor should be plotting another approach to the enlightenment of his charges.

\section{Approximate timing}

How can a tutor get close to the spirit of his doctors in training? This kind of proximity can be uncomfortable to the trainee unused to concepts of personal change. Nevertheless, approximation of the self to the patient is the task to which psychiatrists-intraining must accustom themselves. In this, as in so much else, timing is all.

Some tutors have an office with an ever-open door, so that trainees have access to them whenever difficulties arise. This has not been my way; the door to my office is usually shut, occasionally locked. Next to my office is a doctors' sitting room which contains five or six armchairs, another four or five simpler chairs, pleasant decoration, coffee, a small fridge, a small bookcase and a simple table. All medical staff are welcome to use this common room whenever they want coffee, company or casual reading.

The junior doctors select a time when most of them are able to come together for an hour or so to talk to me about whatever concerns they may have. At Knowle, Tuesdays at 11.00 a.m. seem suitable. Above all, the timing is approximate. Juniors do not attend every week or turn up on the dot. I set a good example by forgetting to show up or appearing half an hour late from time to time. Usually, I bring in a few books and put them on the table. Discussion is free-flowing and I often bore trainees by talking about my anxieties concerning the junior rotation, assessment forms, the membership examination, doctors' accommodation, the emergency rota, medical students and so on. The young doctors are generally understanding about this and learn (which is polite) to look after their tutor who is in difficulties.

In return, I bring the books which form a scatterbrained library accumulated over the years and which constantly changes. Young doctors will be asked at Senior Registrar Appointments Committees: "Apart from the standard textbooks and important papers, 
what psychiatric books have you read?". Often I have sat through the nonplussed silence which follows. I cannot see the difficulty here. The principle is one of homeography: People should read what they find interesting. Some trainees enjoy outstanding general critiques of psychiatry like Leston Haven's Approaches to the Mind or Elaine Showalter's The Female Malady; trainees who like children should read Nabokov's Speak Memory; scientific trainees should read Jacob's The Logic of Life; trainees with an interest in addiction should read Alethea Hayter's Opium and the Romantic Imagination; pregnant trainees should read something by Winnicott; homosexual trainees should read Helen Perry's biography of Sullivan Psychiatrist of America; religious trainees may be encouraged by William James on Varieties of Religious Experience. And there are many other kinds of trainee-stammering, aesthetic, black, promiscuous, aristocratic or sporting types who present individual challenges which the well-equipped tutor can answer from his office bookshelf. I do not give references here because trainees must learn how to be pleasant to the hospital librarian and find access to the required literature. Of course, the librarian has a right to the tutor's support with her own struggles and difficulties.

Also, the tutor is the co-author of his trainees' curricula vitae. As such, he can help tailor each production for each job application and cross-examine his victim in rehearsal for the job interview. Many youngsters worry about research. Most psychiatrists have never done any research of importance but the fallacy is perpetuated that research is something which all registrars should undertake. This is a foolish deception. Any registrar with a typical clinical load and normal human responsibilities has his time cut out passing examinations and mastering the tools of the trade - in particular, the skills of the clinical interview. It baffles me how ordinary, humane, intelligent registrars can acquire good, professional research experience; indeed, I am customarily suspicious of people who say they do. Still, everyone needs a hobby. Worst of all, some trainees get their name added on as 5th author on a tacky paper about, say, antidepressants only to develop a lasting immunity to all research endeavour. A bad experience of poor research is the last thing I would wish on a trainee of mine. My aphorism is: "Let nothing be published under your name unless it requires publication". Junior doctors can distinguish themselves in administrative ability, scholarly research, teaching, travel to foreign parts and so on. Scientific research is frequently fool's gold and very definitely a soft currency in the exchange of curricula vitae.

The development of approximate timing enables a tutor to transmit views such as those (or opposing views) within the organisation in which he and his trainees work. Only anxiety will block the communication of such fundamental truths. With this in mind, we may turn to other matters of future importance. As we do so, we should remark that all trainees should keep a personal diary of their training (a kind of personal psychology) and be required to re-read the stories which they knew in their childhood. At Knowle, The Wind in the Willows has been something of a chart-topper in this way of reaching the child-like centres of the professional self.

\section{The future psychiatric tutor}

My own appointment as Tutor at Knowle was jointly agreed between the College and Southampton University. As things have turned out, I do not think either body has been critical in determining my way of work. It might be fruitful to think of trainees as embryonic consultants but even more fruitful to consider their future as psychiatric tutors. In the changing structure of the National Health Service, especially with the dispersal of services, the unit manager and the tutor have a lot to offer each other in complementary bodies of knowledge and intellectual styles. The concept of the hospital as an educational centre is a good one; the usual psychiatric trainee is more in need of managerial skills than of research skills. Managers must understand that consultants are special and that thinking time (reflection as a professional turn of mind) is not wasted time. Doctors who turn aside from the salaried professionalism of the National Health Service and assume the guise of the entrepreneur must pay the price and earn the income.

What could one say to a future tutor? There is a lot of work to be done. Where are the rewards to be found? Not in financial terms and only occasionally in the personal development of self or others. I find this a difficult area - to say where a tutor should find his reward. It would be unhelpful if it took the form of writing essays for the Bulletin, essays motivated by emotional need-they really would make for undesirable reading. 